\title{
Effects of Vitamin E-Enriched Egg Yolk on Lipid Peroxidation, Hemolysis and Serum Lipid Concentration in Young and Old Rats
}

\author{
Yasuko Yoshizawa, ${ }^{1}$ Tadahiro Miki, ${ }^{1}$ Hiroshi OKamatsu, ${ }^{1}$ \\ Fumio FUKUI, ${ }^{1}$ and Yuriko TAKAI ${ }^{2}$ \\ ${ }^{1} R \&$ D Center, Showa Sangyo Co., Ltd., 2-20-2 Hinode, \\ Funabashi, Chiba 273, Japan \\ ${ }^{2}$ Chiba College of Health Science, 2-10-1 Wakaba-cho, \\ Chiba, Chiba 260, Japan \\ (Received June 18, 1990)
}

\begin{abstract}
Summary Effects of a diet containing different amount of vitamin E-enriched egg yolk powder on lipid peroxidation, hemolysis, and serum lipid concentration were examined in young and old rats. Young and old rats were fed experimental diets containing $5.6 \%$ or $22.5 \%$ of normal egg yolk powder, and $5.6 \%$ or $22.5 \%$ of vitamin E-enriched egg yolk powder. When young rats were fed these diets, their tocopherol concentrations in testes, heart, kidneys, and retroperitoneum fat pads increased according to the diet tocopherol contents. Lipid peroxide levels in these tissues were inversely proportional to the tocopherol concentrations. The liver and serum, however, did not show the above relationship. In the rats fed vitamin E-enriched egg yolk diets hemolysis did not increase, in contrast to those fed normal egg yolk diets. The rats fed a 5.6\% vitamin E-enriched egg yolk diet had a lower serum cholesterol level than those fed a normal egg yolk diet. In old rats, one control group was used to determine initial tocopherol concentration and two other groups were fed 5.6\% normal and vitamin E-enriched egg yolk diets. The vitamin E-enriched egg yolk rats showed lower weights of the body, liver, and retroperitoneum fat pads at the end of the experiment. The normal egg yolk group had atrophied testes. The tissue and serum tocopherol concentrations were increased in the vitamin E-enriched egg yolk group, whereas they were decreased in the normal egg yolk group. In the vitamin E-enriched egg yolk group, lipid peroxide, hemolysis and serum cholesterol, especially HDL-cholesterol, did not increase. These results indicate that egg yolk tocopherol was absorbed and prevented lipid peroxidation and hemolysis in young and old rats, and testes atrophy in old rats.
\end{abstract}

Key Words vitamin E, hemolysis, lipid peroxide, cholesterol, testes, vitamin E-enriched eggs 
Tocopherol has been reported to suppress lipid peroxidation $(1,2)$, erythrocyte hemolysis by diarulic acid $(3,4)$, and plasma cholesterol increases (5). Because of these effects it has recently captured public attention from the viewpoint of aging. Many studies on tocopherol have been reported, yet most were performed using synthetic tocopherol which was either added to the diet or forcibly orally administered.

Eggs containing a high level of vitamin $\mathrm{E}$ in their yolks are available from chickens fed natural tocopherol. Since vitamin E exists in a lipoprotein form in egg yolk, we examined whether natural vitamin $\mathrm{E}$ in egg yolk can suppress lipid peroxidation, hemolysis, and an increase in serum cholesterol in young and old rats.

\section{METHODS}

\section{Materials}

Egg yolks containing a high level of vitamin E (referred to vitamin E-enriched egg yolk) were obtained from chickens fed a large amount of tocopherol derived from soybean oil. Commercial egg yolks were used as control.

Egg yolk powder was obtained after boiling and then lyophilizing. Their tocopherol contents were shown in Table 1. Vitamin E-enriched and commercial egg yolks had little differences in protein, fat and ash contents (data not shown).

\section{Experimental set-up}

Experiment 1. Male 15-week-old Wistar rats were used. They were individually housed in wire-mesh cages in an air conditioned room (temperature 23士 $1^{\circ} \mathrm{C}$, humidity $50 \pm 10 \%$ ) that had its lights on from 0700 to 1900 and fed a commercial nonpurified diet (Type CE-II, Clea Japan, Inc.) for 10 days before commencement of the experimental diets. Four groups having five animals in each group were used, i.e., N-5.6, N-22.5, E-5.6, and E-22.5, with each group being fed a diet of either $5.6 \%$ or $22.5 \%$ normal egg yolk or vitamin E-enriched egg yolk powder for 11 weeks. Diets and water were provided ad libitum. The composition, tocopherol contents, and vitamin E/polyunsaturated fatty acids (PUFA) of their experimental diets are shown in Table 2 . The protein and fat contents in diets of $\mathrm{N}$ 5.6 and E-5.6 were adjusted, by adding vitamin-free casein and lard, to match those in diets of $\mathrm{N}-22.5$ and E-22.5.

Food intake and body weight for each rat were measured every other day

Table 1. Tocopherol contents in lyophilized egg yolk powder.

\begin{tabular}{ccccc}
\hline Egg yolk powder & $\alpha$-toc. & $\beta$-toc. & $\gamma$-toc. & $\delta$-toc. \\
\hline & \multicolumn{4}{c}{$(\mathrm{mg} / 100 \mathrm{~g})$} \\
Normal & 3 & N.D. $^{\text {a }}$ & 2 & N.D. \\
Vitamin E-enriched & 9 & 2 & 96 & 13 \\
\hline
\end{tabular}

\footnotetext{
a Not detected.
} 
Table 2. Experimental diet and content compositions of tocopherol and vitamin E/ polyunsaturated fatty acids (PUFA).

\begin{tabular}{|c|c|c|c|c|}
\hline Ingredient & N-5.6 & E-5.6 & $\mathrm{N}-22.5$ & E-22.5 \\
\hline & \multicolumn{4}{|c|}{$(\%)$} \\
\hline Egg yolk powder & & & & \\
\hline Normal & 5.6 & - & 22.5 & - \\
\hline Vitamin E-enriched & - & 5.6 & - & 22.5 \\
\hline Corn starch & 45.45 & 45.15 & 43.45 & 43.45 \\
\hline Vitamin-free casein & 23.2 & 23.2 & 17.9 & 17.9 \\
\hline Salt mixture $^{a}$ & 6.0 & 6.0 & 6.0 & 6.0 \\
\hline Vitamin mixture $^{\mathrm{b}}$ & 2.0 & 2.0 & 2.0 & 2.0 \\
\hline Cellulose powder & 8.0 & 8.0 & 8.0 & 8.0 \\
\hline $\operatorname{Lard}^{\mathrm{c}}$ & 9.6 & 9.9 & - & - \\
\hline \multirow[t]{2}{*}{ Cholin chloride } & 0.15 & 0.15 & 0.15 & 0.15 \\
\hline & \multicolumn{4}{|c|}{ (mg/100g diet) } \\
\hline $\begin{array}{l}\text { Total tocopherol content } \\
\text { (as } \alpha \text {-tocopherol) }{ }^{\mathrm{d}}\end{array}$ & 0.35 & 5.79 & 0.73 & 22.52 \\
\hline Vitamin E/PUFA ${ }^{\mathrm{e}}$ & 0.27 & 4.79 & 0.48 & 13.49 \\
\hline
\end{tabular}

during the 11-week experimental period. Initially, and on week 3,5 , and 11, blood was taken from the tail vein and red blood cells were separated for use in the hemolysis tests.

Experiment 2. Male 36-week-old Wistar rats were used which were housed under the same conditions and fed the same commercial nonpurified diet for 4 weeks before commencement of the experimental diets. Three groups having 7 animals in each group were used with one group being a "control group" to determine the tissue and serum tocopherol concentrations at the initiation, and two other groups, i.e., N-5.6 and E-5.6, being fed for 28 weeks a respective diet of either $5.6 \%$ normal egg yolk or vitamin E-enriched egg yolk powder. Feeding conditions were similar to Experiment 1, and blood was also similarly drawn for hemolysis tests initially and on week 13,18 , and 28.

After the experimental feeding, the rats were sacrificed by decapitation, their blood collected and tissues excised. All serum and tissues were stored at $-20^{\circ} \mathrm{C}$ until analyzed. Some liver and brain tissues were subjected to histological observations before the storage.

\section{Analytical methods}

Hemolysis test. The hemolysis in percent was determined using diarulic acid 
by the method of Friedman et al.(6).

Tocopherol determination. Tissue tocopherol concentrations were determined after saponification by HPLC. Samples $(1.5-2.0 \mathrm{~g})$ were saponificated in $20 \mathrm{ml}$ of $5 \% \mathrm{KOH} /$ ethanol with $0.4 \mathrm{~g}$ of pyrogallol, followed by the addition of $40 \mathrm{ml}$ of water, and then the samples were extracted 3 times using diethylether. The extracts having alkali were washed out with water. After evaporation the residues were resolved in $n$-hexane and assayed by a HPLC system. The conditions and instruments of the HPLC system were as follows; HPLC: Shimadzu LC-5A, column: SHIM-PACK FLC-NH ${ }_{2}$, eluent: $n$-hexane-isopropylether-ethanol (446.5 : $5.2: 1.5$ ), flow rate: $1.5 \mathrm{ml} / \mathrm{min}$, detector: Shimadzu RF-530 fluorescent HPLC monitor (excitation wavelength: $298 \mathrm{~nm}$, emission wavelength: $325 \mathrm{~nm}$ ), integrator: Shimadzu C-R1B.

Serum tocopherol was extracted with diethylether from $2.0 \mathrm{ml}$ of serum, added to $10 \mathrm{ml}$ of distilled water and $10 \mathrm{ml}$ of ethanol, with the extracts then being evaporated. The residues were resolved in $n$-hexane and assayed by HPLC.

Lipid peroxide determination. Lipid peroxides were determined as thiobarbituric acid (TBA) values. Serum TBA values were assayed by the method of Yagi (7), and tissues by the method of Oishi (8).

Lipid determination. Serum total cholesterol, high density lipoprotein (HDL) cholesterol, and triglycerides were determined by enzymatic procedures using commercial kits, Determiner TC “555," Determiner HDL, and Determiner TG (Kyowa Medex Co., Ltd.) respectively. Total liver cholesterol was determined after saponification.

Lipofuscin pigment histological observation. Small pieces of liver and brain tissue were treated with hematoxylin-eosin staining and periodic acid-Schiff staining (9).

\section{RESULTS AND DISCUSSION}

Experiment 1. The effects of vitamin E-enriched egg yolks on young rats (15 weeks) were examined. No influence on growth and food consumption were observed (Table 3). In weanling rats fed a vitamin E-deficient diet, their growth was not influenced until 30 weeks old, after which it was delayed when compared

Table 3. Body weight and food consumption average in Experiment 1.

\begin{tabular}{lcc}
\hline Group & $\begin{array}{c}\text { Body weight gain } \\
(\mathrm{g} / \text { day })\end{array}$ & $\begin{array}{c}\text { Food consumption } \\
(\mathrm{g} / \text { day })\end{array}$ \\
\hline $\mathrm{N}-5.6$ & $2.4 \pm 0.2^{\mathrm{a}}$ & $19.3 \pm 0.6$ \\
$\mathrm{E}-5.6$ & $2.3 \pm 0.1$ & $18.7 \pm 0.5$ \\
$\mathrm{~N}-22.5$ & $2.1 \pm 0.2$ & $18.8 \pm 0.4$ \\
E-22.5 & $2.5 \pm 0.2$ & $19.0 \pm 0.7$ \\
\hline
\end{tabular}

${ }^{\text {a }}$ Mean \pm SEM. 
Table 4. Tissue weights after experimental feeding in Experiment 1.

\begin{tabular}{lccc}
\hline Group & Live & $\begin{array}{c}\text { Testes } \\
(\mathrm{g} / 100 \mathrm{~g} \text { body weight })\end{array}$ & Heart \\
\hline N-5.6 & $3.75 \pm 0.05^{\mathrm{a}}$ & $0.59 \pm 0.17$ & $0.25 \pm 0.01$ \\
E-5.6 & $3.86 \pm 0.16$ & $0.57 \pm 0.01$ & $0.22 \pm 0.01^{\mathrm{b}}$ \\
N-22.5 & $4.05 \pm 0.11$ & $0.60 \pm 0.02$ & $0.25 \pm 0.05$ \\
E-22.5 & $4.10 \pm 0.22$ & $0.57 \pm 0.02$ & $0.24 \pm 0.01$ \\
\hline \multicolumn{3}{|c}{ Retroperitoneum fat pads } \\
Group & Kidneys & \multicolumn{2}{c}{$2.93 \pm 0.20$} \\
& & \multicolumn{2}{c}{$3.60 \pm 0.21$} \\
N-5.6 & $0.63 \pm 0.02$ & \multicolumn{2}{c}{$2.80 \pm 0.26$} \\
E-5.6 & $0.61 \pm 0.01$ & \multicolumn{2}{c}{$3.22 \pm 0.24$} \\
N-22.5 & $0.59 \pm 0.02$ & gody weight $)$ \\
E-22.5 & $0.62 \pm 0.02$ & \multicolumn{2}{c}{. }
\end{tabular}

${ }^{\mathrm{a}}$ Mean \pm SEM. ${ }^{\mathrm{b}}$ Significantly different from N-5.6 $(p<0.05)$.

to rats fed a vitamin E-sufficient diet $(10,11)$. The data in the present study indicates that vitamin $\mathrm{E}$ content did not influence the growth until 27 weeks old.

Rat tissue weights are given in Table 4, and the heart weight in E-5.6 was significantly smaller than in N-5.6. The weights of retroperitoneum fat pads in E5.6 and E-22.5 were larger when compared with respective controls, and this is consistent with Hirahara et al. who reported that the retroperitoneum and epidermal fat pad weights of rats fed vitamin E-deficient diets were smaller during the growing period (10). Takeuchi et al. reported an increase in synthesis of cholesterol and fatty acids during vitamin E supplementation (5), hence the larger fat pad weights in E-5.6 and E-22.5 were mostly attributable to lipid metabolism changes. It was reported that the testes of vitamin E-deficient rat became atrophied (10), but in this study no observable differences were found between the control and experimental groups.

Figure 1 shows tissue tocopherol contents. No $\beta$ - and $\delta$-tocopherol were detected, thus the figure shows only $\alpha$ - and $\gamma$-tocopherol results. The $\alpha$-tocopherol content changed according to the tocopherol feeding level, which was directly reflected the $\alpha$-tocopherol concentrations in the testes, kidneys, and retroperitoneum fat pads, but not in the liver. Liver $\gamma$-tocopherol in N-22.5 was higher than that in E-22.5. An only slight $\gamma$-tocopherol content was detected in the testes, heart, and kidneys.

Peroxides in all tissues were determined as TBA reacting substances (Fig. 2), with N-5.6 showing the largest value. This indicates that egg yolk tocoherol prevented lipid peroxidation. In the liver and testes no significant differences in TBA values were found among E-5.6, N-22.5, and E-22.5. TBA values in the testes, heart, and kidneys were inversely proportional to the tissue tocopherol concentrations: respective correlation coefficients were $-0.88,-0.87$, and $-0.92(n=$ 


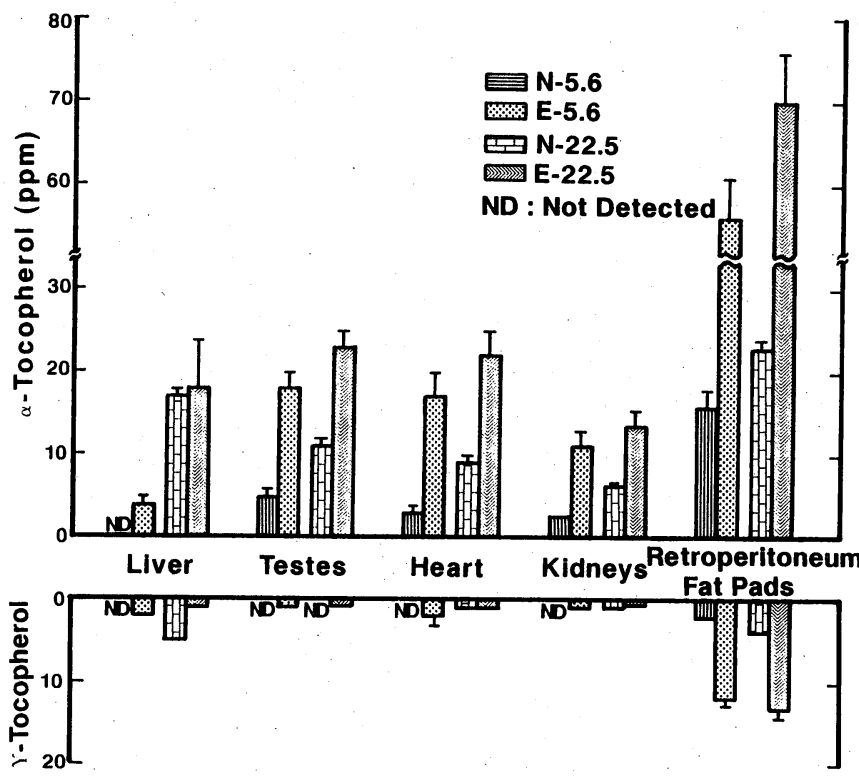

Fig. 1. Rat tissue $\alpha$-and $\gamma$-tocopherol concentrations in Experiment 1, with means \pm SEM from 5 rats.

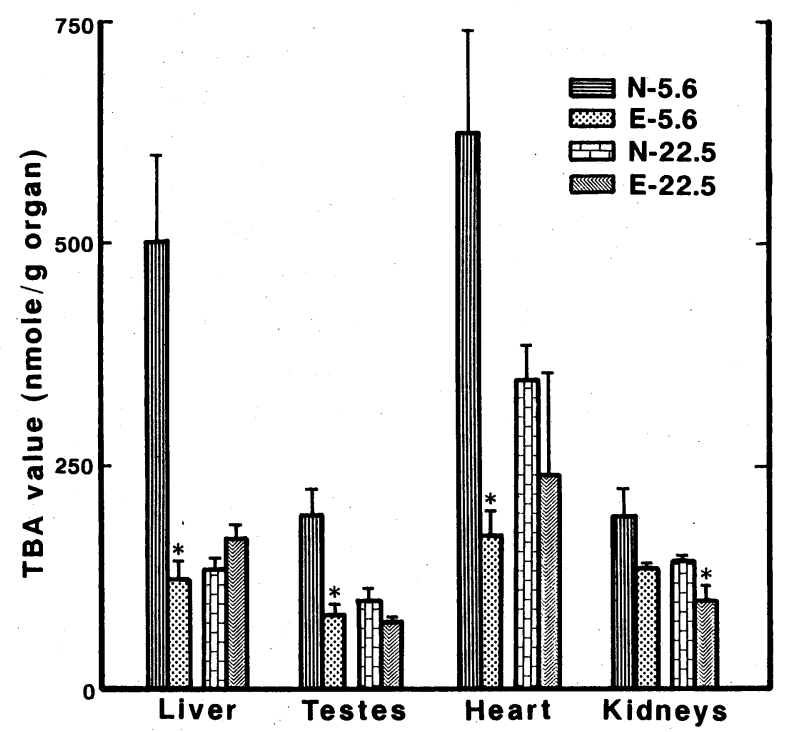

Fig. 2. Rat tissue TBA values in Experiment 1, with means \pm SEM from 5 rats. Asterisks on E-5.6 indicate a significant difference $(p<0.05)$ from N-5.6, and on E-22.5 a significant difference $(p<0.05)$ from N-22.5. 
20).

The hemolysis percent in N-5.6 and N-22.5 increased on 3 and 5 weeks respectively. On the contrary, E-5.6 and E-22.5 showed an approximate zero hemolysis percent throughout the experimental period (Fig. 4). These results are consistent with previous reports that vitamin E-deficient rats have a tendency to show hemolysis.

The tocopherol concentrations and TBA values in the liver (Figs. 1 and 2) and in serum (Fig. 3) were not influenced by the tocopherol supplement amount. The $\alpha$-tocopherol concentration in the E-5.6 group was higher than that in the N-5.6 group with lower TBA values. TBA values in E-22.5 were higher when compared

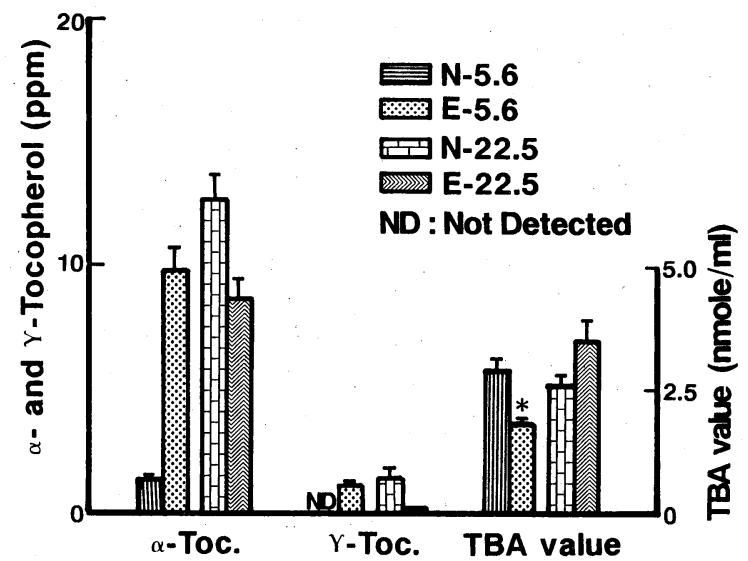

Fig. 3. Serum $\alpha$ - and $\gamma$-tocopherol concentrations and TBA values in Experiment 1 , with means \pm SEM from 5 rats. Asterisk on E-5.6 indicates a significant difference $(p<0.05)$ from N-5.6.

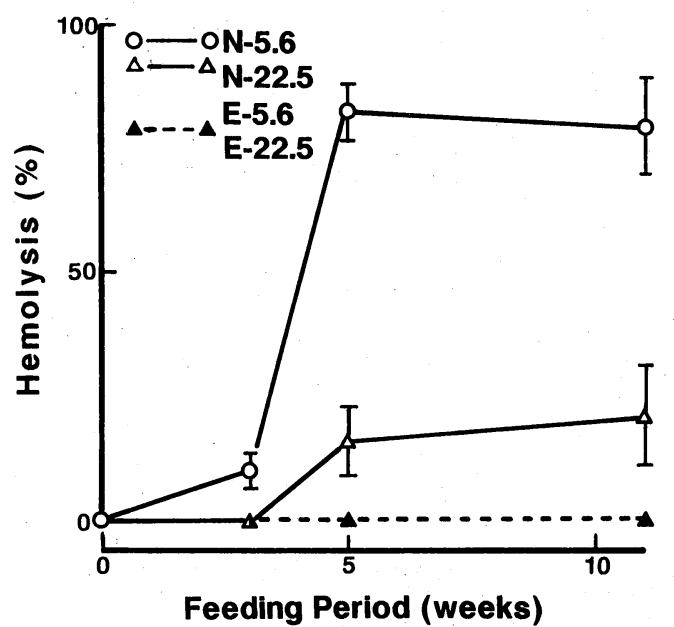

Fig. 4. Percentage hemolysis in Experiment 1, with means \pm SEM from 5 rats. 
to $\mathrm{N}-22.5$, whereas the liver $\alpha$-tocopherol concentration in E-22.5 was similar to $\mathrm{N}$ 22.5. The serum tocopherol concentrations in E-22.5 were lower than N-22.5, and had higher TBA value. The rats in N-22.5 were vitamin E-deficient and the rats in E-22.5 were vitamin E-sufficient according to the hemolysis test results. Therefore the liver and serum tocopherol concentrations and TBA values do not indicate the vitamin E nutritional dependency of the rats, consistent with Krishnamurthy et al. (12). Mouri et al. reported that quality of the dietary protein affected the serum and tissue tocopherol concentrations (13), which may indicate that high liver and serum tocopherol concentrations in $\mathrm{N}-22.5$ are caused by the dietary protein quality when compared to the N-5.6 and E-5.6 results.

The serum cholesterol concentration in E-5.6 was lower than in N-5.6, but no significant differences were detected between E-22.5 and N-22.5. The atherogenic

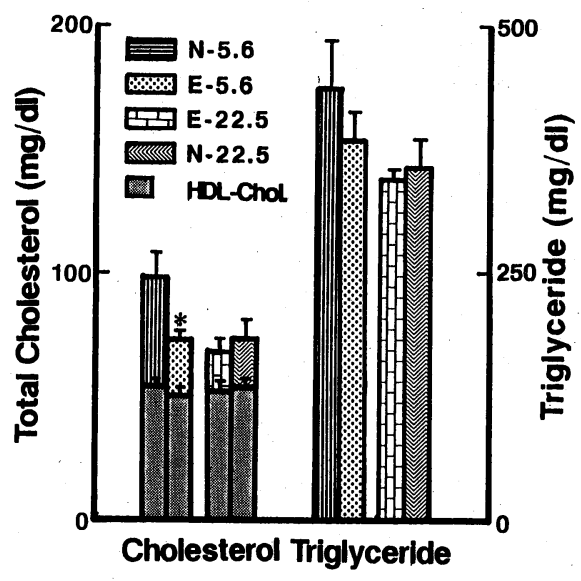

Fig. 5. Serum total cholesterol and triglyceride concentrations in Experiment 1, with means \pm SEM from 5 rats. Asterisk on E-5.6 indicates a significant difference $(p<0.05)$ from N-5.6.

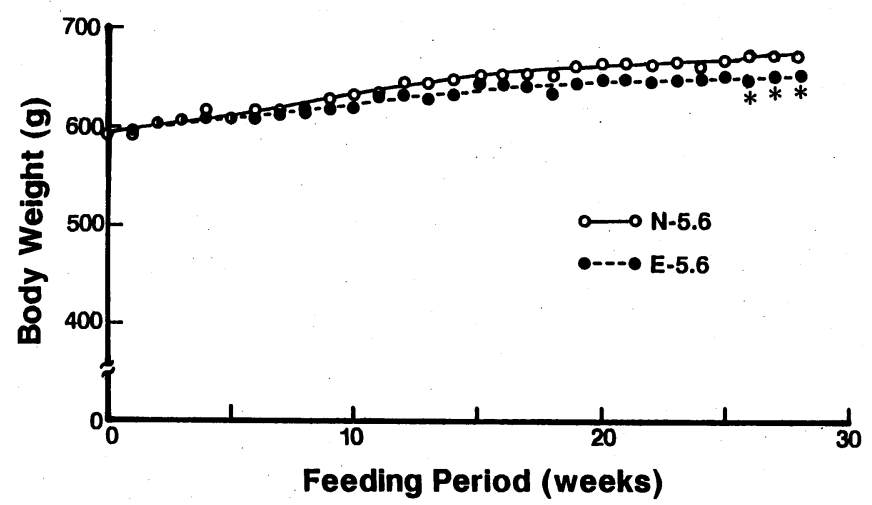

Fig. 6. Mean body weight change over Experiment 2 period. Asterisks indicate a significant difference $(p<0.05)$ from N-5.6. 
index, a ratio of total cholesterol to HDL-cholesterol, and the serum triglyceride concentration showed no significant differences between the four dietary groups (Fig. 5). Several reports have shown that tocopherol lowers serum cholesterol in rats and rabbits (14-16), although other reports showed no effects $(17,18)$. In these experiments the effects of tocopherol on serum cholesterol concentration were different between N-5.6/E-5.6 and N-22.5/E-22.5. It has also been reported that serum tocopherol concentrations were affected by serum lipid concentrations (19), but this effect was not found in the present study.

Experiment 2. Old rats ( 36 weeks) were fed a vitamin E-sufficient diet before experiment initiation.

Changes in body weight are shown in Fig. 6, and in the E-5.6 group the body weights were significantly smaller in the last three weeks than that of N-5.6, although no significant difference in food intake occurred (data not shown).

Tissue weights are shown in Table 5. The testes weights in E-5.6 were higher than N-5.6. White testes tinged with pink were observed during autopsy in the control and E-5.6 group, but the testes in N-5.6 were atrophied and had a pale yellow color. Hirahara et al. reported similar changes in weanling rats fed a vitamin E-deficient diet for 44 weeks (10). The liver and retroperitoneum fat pads in E-5.6 were smaller than in N-5.6.

Tissue and serum tocopherol concentrations are shown in Fig. 7 and Fig. 8, and similarly to Experiment 1, no $\beta$ - and $\delta$-tocopherol were detected. The tissue $\alpha$ tocopherol concentration decreased in N-5.6 and increased in E-5.6 as compared with the control group. The ratio of the N-5.6 to the control group was as follows; liver, 0.27; testes, 0.52; heart, 0.57 ; kidneys, 0.33 ; retroperitoneum fat pads, 0.76 ; serum, 0.16 . This difference in ratio may indicate that the tocopherol accumulated in fat pads might be difficult to utilize. Machlin et al. reported that tocopherol in fat pads is not effectively utilized because of its extremely slow release rate (20), which is consistent with these results. Whereas in E-5.6 the ratios were much larger, i.e., liver, 3.49; testes, 1.90; heart, 2.43; kidneys, 1.34; retroperitoneum fat pads, 2.52; serum, 1.59 .

Table 5. Tissue weights after experimental feeding in Experiment 2.

\begin{tabular}{cccc}
\hline Group & Liver & $\begin{array}{c}\text { Testes } \\
(\mathrm{g} / 100 \mathrm{~g} \text { body weight })\end{array}$ & Heart \\
\hline $\mathrm{N}-5.6$ & $2.79 \pm 0.06^{\mathrm{a}}$ & $0.52 \pm 0.02$ & $0.27 \pm 0.01$ \\
E-5.6 & $2.43 \pm 0.05^{\mathrm{b}}$ & $0.59 \pm 0.02^{\mathrm{b}}$ & $0.25 \pm 0.01$ \\
\hline & & & \\
\hline Group & Kidneys & Retroperitoneum fat pads \\
& & $(\mathrm{g} / 100 \mathrm{~g}$ body weight $)$ \\
\hline N-5.6 & $0.50 \pm 0.02$ & \multicolumn{2}{c}{$3.83 \pm 0.10$} \\
E-5.6 & $0.50 \pm 0.02$ & $3.42 \pm 0.21$ \\
\hline
\end{tabular}

\footnotetext{
${ }^{\mathrm{a}}$ Mean \pm SEM. ${ }^{\mathrm{b}}$ Significantly different from N-5.6 $(p<0.05)$.
} 


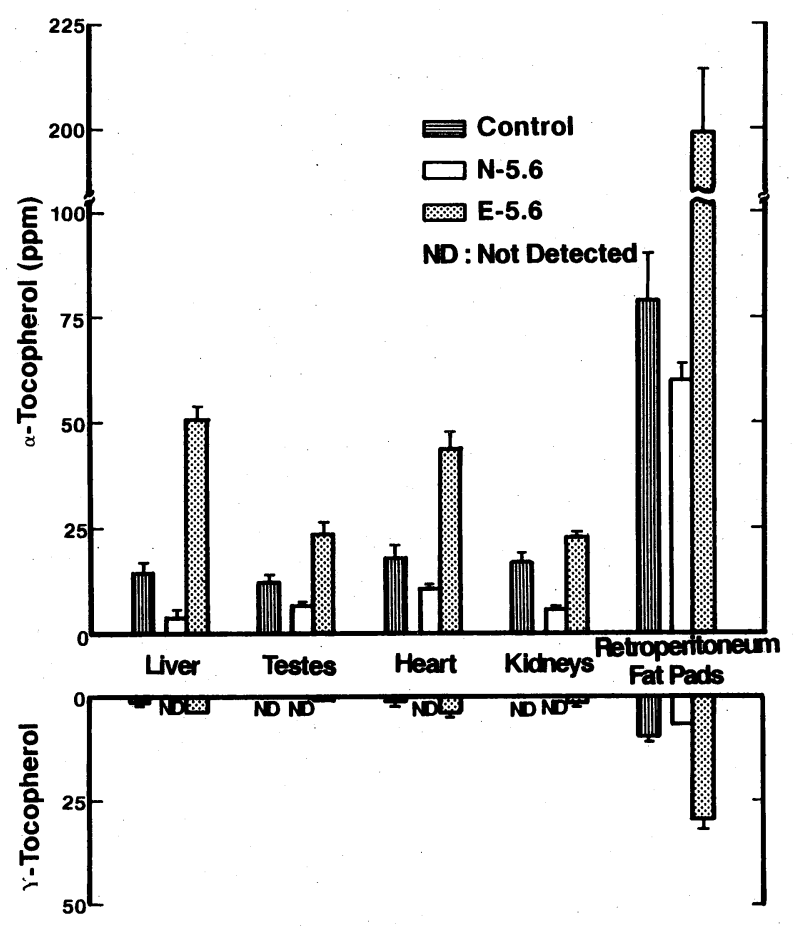

Fig. 7. Tissue $\alpha$ - and $\gamma$-tocopherol concentrations in Experiment 2, with means \pm SEM from 7 rats.

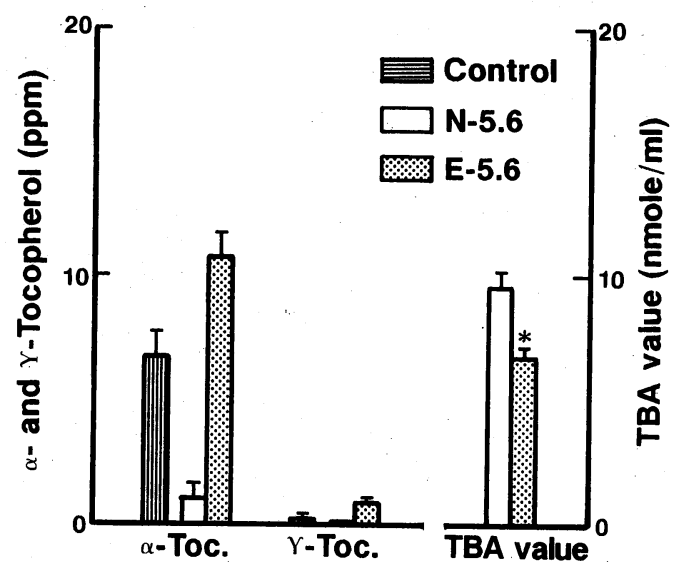

Fig. 8. Serum $\alpha$ - and $\gamma$-tocopherol concentrations and TBA values in Experiment 2 , with means \pm SEM from 7 rats. Asterisk indicates a significant difference $(p<$ $0.05)$ from $\mathrm{N}-5.6$. 
The hemolysis percent in N-5.6 moderately increased from 13 weeks, whereas that in E-5.6 remained approximately the same throughout the experimental period (Fig. 9). In Experiment 1, the N-5.6 hemolysis was already $90 \%$ at 5 weeks after



Fig. 9. Hemolysis percent change over experimental period in Experiment 2, with means \pm SEM from 7 rats.

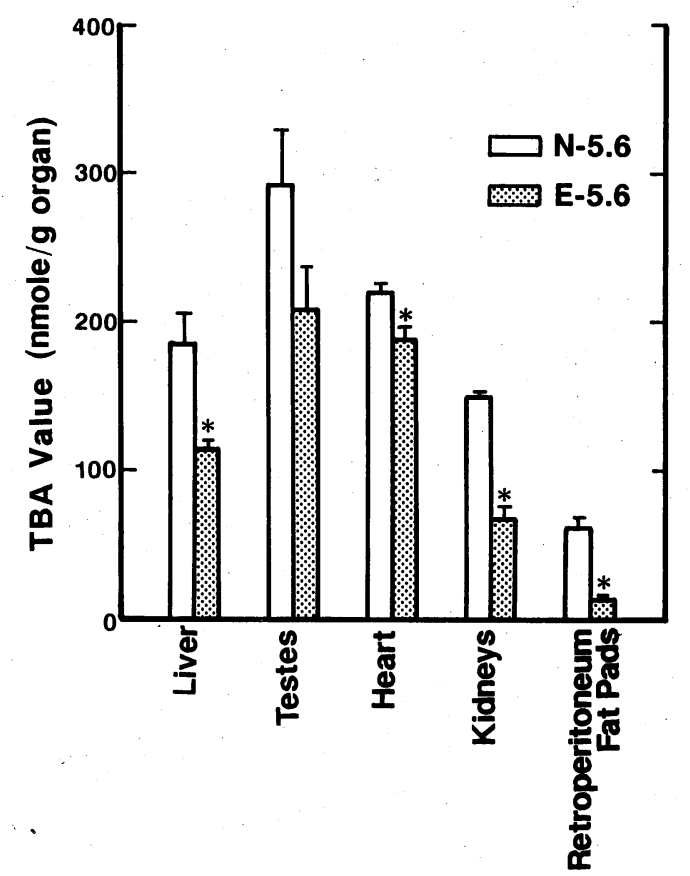

Fig. 10. Tissue TBA values in Experiment 2, with means \pm SEM from 7 rats. Asterisks indicate a significant difference $(p<0.05)$ from N-5.6. 
Table 6. Liver and brain lipofuscin pigments incidence in Experiment 2.

\begin{tabular}{ccc}
\hline Group & Liver & Brain \\
\hline N-5.6 & $2 / 7$ & $0 / 7$ \\
E-5.6 & $0 / 7$ & $0 / 7$ \\
\hline
\end{tabular}

commencement, but in this experiment the maximum N-5.6 value at the end of the experiment was only $19 \%$.

The deficiency symptoms appear more slowly in old rats than in young rats so far as the hemolysis was used as an index of vitamin E deficiency. The tendency of a larger vitamin $\mathrm{E}$ requirement upon aging was not found, a result contrary to Gabriel et al. (21).

In Experiment 1, even though the hemolysis immediately increased, the N-5.6 testes did not show any changes. We believe, therefore, that vitamin E deficiency symptoms appear in a different manner for young and old rats; a vitamin $\mathrm{E}$ deficiency appeared to have a strong influence on the testes of old rats.

Tissue and serum peroxides were detected as TBA reacting substances (Fig. 8 and Fig. 10), and all values in E-5.6 were lower than in N-5.6. Lipofuscin pigments were observed in only two livers in N-5.6 rats, not in any E-5.6 livers, nor in the brains of either group (Table 6). Menken et al. reported that brain organic solvent-soluble lipofuscin pigments in vitamin E-deficient rats were not different from vitamin E-sufficient rats (22), while Akazawa reported that TBA values in vitamin E-deficient rats increased when compared with vitamin E-sufficient rats (23).

Serum cholesterol and triglyceride concentrations are shown in Fig. 11. The

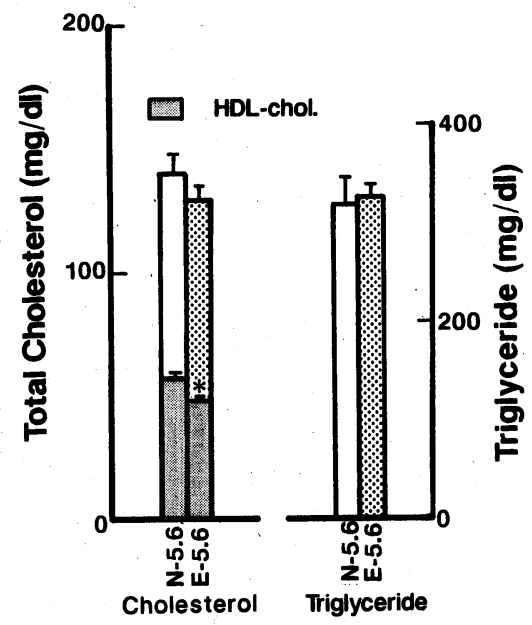

Fig. 11. Serum total cholesterol, HDL-cholesterol, and triglyceride in Experiment 2 , with means \pm SEM from 7 rats. Asterisk indicates a significant difference $(p<$ 0.05 ) from N-5.6. 




Fig. 12. Liver total cholesterol levels in Experiment 2, with means \pm SEM from 7 rats.

serum cholesterol in E-5.6 was lower than N-5.6, causing a significant decrease in HDL-cholesterol. In contrast to the present study Hermann Jr. et al. reported that tocopherol in humans has a tendency to increase HDL-cholesterol (24). The reason for this discrepancy is unknown.

The hepatic cholesterol in E-5.6 was generally lower than in N-5.6 (Fig. 12). Takeuchi et al. reported that hepatic cholesterol and fatty acid synthetic activities were lowered in microsomes of vitamin E-deficient rats, and that conformational change in a microsomal membrane may impair degradative enzymes just as much as synthetic activity does (14). It may be concluded that hepatic cholesterol metabolic activity decreased, and that the liver weight increase in N-5.6 is due to lipid accumulation caused by a reduction in these enzymatic activities. Hirahara $e t$ al. (10) and Nakashima et al. (11) reported that rats fed a vitamin E-deficient diet showed delayed growth, inconsistent with the present results. The larger body weight in N-5.6 may be due to the increase in liver and fat pads weights.

Several studies concerning the tocopherol amount required to prevent erythrocyte hemolysis in rats have been reported. Inagaki et al. found that rats require $100-500 \mu \mathrm{g}$ of $\alpha$-tocopherol per day (25). Alfin-Slater et al. demonstrated that a vitamin E/PUFA ratio of $0.37 \mathrm{mg} / \mathrm{g}(26)$ is needed. In Experiment 1 young vitamin E-deficient rats (N-22.5) were fed tocopherol of approximately $140 \mu \mathrm{g}$ per day, and had a vitamin E/PUFA ratio of 0.48 . Both the young vitamin E-sufficient rats in Experiment 1 and the old and vitamin E-sufficient rats in Experiment 2 (E-5.6) were fed tocopherol of approximately 1,080 and $840 \mu \mathrm{g}$ per day respectively and had a vitamin E/PUFA ratio of 4.79 .

Experiment 1 and 2 results indicate that egg yolk tocopherol ingested as part of the diet prevented lipid peroxidation, hemolysis, and testes atrophy. It remains to be seen whether the natural tocopherol existing in lipoprotein offers some advantage over synthetic tocopherol in rats. 


\section{REFERENCES}

1) Noguchi, T., Cantor, A. H., and Scott, M. L. (1973): Mode of action of selenium and vitamin $\mathrm{E}$ in prevention of exudative diatheses in chicks. J. Nutr., 103, 1502-1511.

2) Tappel, A. L. (1962): Vitamin $\mathrm{E}$ as the biological lipid antioxidant. Vitamins Hormones, 20, 493-510.

3) Rose, C. S., and Gyorgy, P. (1950): Tocopherol requirements of rats by means of the hemolysis test. Proc. Soc. Exp. Biol. Med., 74, 411-415.

4) Bieri, J. G., and Poukka, R. K. H. (1970): In vitro hemolysis as related to rat erythrocyte content of $\alpha$-tocopherol and polyunsaturated fatty acids. J. Nutr., 100, 557-564.

5) Takeuchi, N., Tanaka, F., Katayama, Y., Matsumiya, K., and Yamaura, Y. (1976): Effects of $\alpha$-tocopherol on thiobarbituric acid reactive substances in serum and hepatic subcellular organelles and lipid metabolism. Exp. Gerontol., 11, 179-185.

6) Friedman, L., Weiss, W., Wherry, F., and Kline, O. L. (1958): Bioassay of vitamin E by the dialuric acid hemolysis method. J. Nutr., 65, 143-160.

7) Yagi, K. (1975): Micro-determination of lipoperoxide in blood plasma or serum. Vitamins (Japan), 49(9, 10), 403-405.

8) Oishi, N. (1978): Determination of lipid peroxide. The Saishinigaku (in Japanese), 33, 660-663.

9) Sano, Y. (1972): Soshikigaku Kenkyuho (in Japanese), 4th ed., Nanzando's publications, Tokyo, pp. 455-456.

10) Hirahara, F., Takai, Y., and Iwao, H. (1979): Effects of tocopherol on changes of absorption of nutrients and weights of body and tissues with the process of aging in rats. Nutr. Rep. Int., 20, 251-259.

11) Nakashima, Y., and Esashi, T. (1986): Age-related changes in sympathetic nervous activity of rats receiving vitamin E-deficient diet. J. Nutr. Sci. Vitaminol., 32, 569-579.

12) Krishnamurthy, S., and Bieri, J. G. (1963): The absorption, storage, and metabolism of $\alpha$-tocopherol- ${ }^{14} \mathrm{C}$ in the rat and chicken. J. Lipid Res., 4(3), 330-336.

13) Mouri, K., Hayafune, Y., and Igarashi, O. (1986): Effect of dietary protein on vitamin E levels in erythrocytes and tissues of rats. J. Nutr. Sci. Vitaminol., 32(2), 147-155.

14) Takeuchi, N., Matsumiya, K., Takahashi, Y., Higashino, K., Tanaka, F., and Katayama, Y. (1977): Thiobarbituric acid reactive substances and lipid metabolism in $\alpha$ tocopherol deficient rats. Exp. Gerontol., 12, 63-68.

15) Sho, H., and Yamashiro. I. (1977): Effect of tocopherol on serum cholesterol and triglyceride of male rats fed sugar diets. J. Jpn. Soc. Nutr. Food Sci., 30(6), 367-370.

16) Westrope, K. L., Miller, R. A., and Wilson, R. B. (1982): Vitamin E in a rabbit model of endogenous hypercholesterolemia and atherosclerosis. Nutr. Rep. Int., 25(1), 8388.

17) Cho, S., and Sugano, M. (1978): Effect of different levels of dietary $\alpha$-tocopherol and linoleate on plasma and liver lipids in rats. J. Nutr. Sci. Vitaminol., 24, 221-227.

18) Yang, N. Y. J., and Desai, I. D. (1977): Effect of high levels of dietary vitamin E on liver and plasma lipids and fat soluble vitamins in rats. J. Nutr., 107, 1418-1426.

19) Bieri, J. G., Everts, R. P., and Sylvia, T. (1977): Factors affecting the exchange of tocopherol between red blood cell and plasma. Am. J. Clin. Nutr., 30, 686-690. 
20) Machlin, L. J., and Gabriel, E. (1982): Kinetics of tissue $\alpha$-tocopherol uptake and depletion following administration of high levels of vitamin E. Ann. N.Y. Acad. Sci., 393, 48-60.

21) Gabriel, E., Machlin, L. J., Filipski, R., and Nelson, J. (1980): Influence of age on the necrotizing myopathy. J. Nutr., 110, 1372-1379.

22) Menken, B. Z., Le-Chu Su, Ayaz, K. L., and Saari Csallany, A. (1986): Organic solvent-soluble lipofuscin pigments and glutathion peroxidase in mouse brain and heart: Effects of age and vitamin E. J. Nutr., 116, 350-355.

23) Akazawa, N. (1983): The effects of vitamin E deficiency and/or dietary fish oil on the lipid peroxide and histology of some organs. J. Home Econom. Jpn., 34(3), 133-139.

24) Hermann, W. J., Jr., Ward, K., and Faucett, J. (1979): The effect of tocopherol on high-density lipoprotein cholesterol. A clinical observation. Am. J. Clin. Pathol., 72, 848-852.

25) Inagaki, C., Sugawa, Y., and Maki, C. (1967): Studies on the effects of $\alpha$-tocopherol upon the metabolism of unsaturated fatty acid. Vitamins (J. Vitamin Soc. Jpn.), 36, 296-300.

26) Alfin-Slater, R. B., Shimma, Y., Hansen, H., Wells, P., and Aftergood, L. (1972): Dietary fat composition and tocopherol requirement. J. Am. Oil Soc., 49, 395-402.

27) Horwitt, M. K. (1982): Physiology and nutrition of vitamin E. J. Jpn. Soc. Nutr. Food Sci., 35(4), 253-263. 